\title{
El-tipi LiDAR nokta bulutundan tek ağaç gövdesinin otomatik çıkarımında istatistiksel sınıflandırma algoritmalarının performans analizi
}

\author{
Performance analysis of statistical classification algorithms in automatic extraction of single tree trunk from hand-held \\ LiDAR point cloud
}

Mustafa ZEYBEK

Artvin Çoruh Üniversitesi Mühendislik Fakültesi Harita Mühendisliği Bölümü, Artvin, Türkiye

\begin{tabular}{l} 
Eser Bilgisi / Article Info \\
Araştırma makalesi / Research article \\
DOI: 10.17474/artvinofd.689894 \\
\hline Sorumlu yazar / Corresponding author \\
Mustafa ZEYBEK \\
e-mail: mzeybek@artvin.edu.tr \\
\hline Geliş tarihi / Received \\
16.02.2020 \\
Düzeltme tarihi / Received in revised form \\
02.05.2020 \\
Kabul Tarihi / Accepted \\
06.05.2020 \\
Elektronik erişim / Online available \\
11.06.2020 \\
\hline Anahtar kelimeler: \\
Lidar \\
Nokta bulutu \\
Ağaç gövdesi \\
Sinılandırma \\
\hline Keywords: \\
Lidar \\
Point cloud \\
Tree stem \\
Classification \\
\hline
\end{tabular}

\begin{abstract}
Özet
Enerjisi ışık veya lazer olan LiDAR yöntemi yoğun koordinat verisini hızlı bir şekilde ölçen bir ölçme tekniğidir. Orman alanlarında kullanımı yaygın olan bu teknik, yoğun bir veri işleme adımına sahiptir. $\mathrm{Bu}$ işlemlerin en başında sınıflandırma gelir. Ağaç parametrelerinin kestiriminde ağaç gövdelerinin doğru tespiti önemli bir konudur. Bu çalışma, el-tipi mobil LiDAR (EML) ile ölçülmüş nokta bulutlarında ağaç gövde modelinin sınıflandırma ile çıkarımında kullanılan yöntemlerin performanslarını değerlendirmek amacıyla yapılmıştır. Tek ağaç bazında EML nokta bulutundan gövdenin tespit edilmesi için istatistiksel sınıflandırma tekniklerinden, lojistik regresyon, doğrusal ayrıştırma analizi, rastgele orman ve destek vektör makinesi kullanılmıştır. Sadece gövdeyi temsil eden noktalar diğer dal ve yapraklardan ayrılarak sınıflandırılmıs, genel doğruluk oranına göre sınıflandırma doğruluğu en yüksek yöntem rastgele orman sınıflandırıcısı olduğu tespit edilmiştir. Veri işleme performansı açısından doğrusal ayrıştırma analizi diğer yöntemlere göre daha iyi performans sergilemiştir.
\end{abstract}

\begin{abstract}
LiDAR method, whose energy is light or laser, is a measurement technique that quickly measures dense spatial data. This technique is widely used in forest areas and has an intensive data processing step. Classification comes first in the mentioned processes. Accurate detection of tree stem is an important issue in predicting tree parameters. This study was conducted to evaluate the performance of the methods used in the classification and extraction of tree stem using point clouds measured by handheld mobile LiDAR system (HMLS). To identify the stems from the HMLS point cloud on a single-tree basis, statistical classification techniques, like logistic regression, linear discriminant analysis, random forest and support vector machine, were used. Only the points representing tree stems were classified by separating them from other parts of the trees, such as branches and leaves. It was determined that the best method was a random forest classifier based on overall accuracy results. In terms of data processing performance, a linear discriminant analysis performed better than the other methods.
\end{abstract}

\section{GiRiş}

Doğal kaynaklarımızın en iyi şekilde işletilmesi, ülke ve yöre halkının optimum faydalanmasına sunulması zorunludur. Bu kaynakların başında mevcut ormanlar ve bunları oluşturan bitki türlerinin çok amaçlı kullanımı dikkate alınarak, maksimum yarar sağlayacak şekilde işletilmesi gerekir. Çok amaçlı yararlanacağımız ağaç türlerinden birisi de kızılağaçlardır. Lazer tarama sistemleri (LTS), belirli bir ölçme alanında jeodezik ölçme sistemleri doğruluğu seviyesinde üç boyutlu (3B) konumsal bilgiyi yüksek çözünürlükte ve hassasiyette sağlamasıyla farklı disiplinler için kullanımı artmaktadır. Hızlı bir ölçme sistemi olması nedeniyle orman alanlarında 3B modelleme ile daha fazla ağaç rekonstrüksiyonunu mümkün kılar ve orman ölçmelerinde dendrometrik çıkarımların yapılmasını kolaylaştırır. Orman envanterinin çıkarımında LTS teknolojisi, nokta bulutlarından envanter bilgilerinin çıkarılmasında zorlu orman koşulları için iyi bir performans sergileyen bir ölçme sistemidir. Özellikle gövdenin çıkarımı ve modellenmesi, orman amenajmanında faydalı hacim miktarının en doğru şekilde hesaplanması hedeflenen önemli değişkenlerden biridir. LTS, orman envanteri aşamasında test alanındaki gövdelerin belirlenmesi için bir potansiyel alternatif teknolojik sistem olarak ortaya çıkmaktadır. 
LTS nokta bulutlarının işlenmesinde temel işlem adımları farklı çalışmalarda belirlenmiş ve bir standart oluşturulmuştur (James ve Quinton 2014, Xiong vd. 2019). Ancak, orman alanları ve ağaç yapısı ile ilgili temel bilgilerin nokta bulutlarından çıkarılmasında gövde segmentasyonunun doğru ve güvenilir bir algoritma ile yapılması üzerine standart ve yüksek performans sunan çalışmalar oldukça az sayıdadır (Heinzel ve Ginzler 2019, Wang vd. 2019, Yrttimaa vd. 2019). Bunun en temel sebebi orman ve ağaç yapılarındaki karmaşıklıklar ve farklılıklardır (Dai vd. 2019).

LTS nokta bulutları uygulama platformu özelliklerine göre farklı sistemlerde gruplandırımaktadır (Zeybek 2019). Havasal LTS, mobil LTS ve yersel LTS olarak gruplandırılan lazer (LiDAR) sistemleri orman envanterinde 20 yıla yakın bir süreden bu yana yaygın olarak kullanılmaktadır (Maltamo vd. 2014).

Havasal LiDAR, uzaktan algılama sisteminin, en güçlü yanı, düşey orman yapısının doğrudan tanımlanması ve ölçülmesidir. Meşçere boyu ölçümü, alt tabaka ve topografyanın tanımlanması, noktaların düşey dağılımı, orman karakterizasyonu ve yönetimi için yoğun bir veri seti sağlar (Dubayah ve Drake 2000). Ağaçların gövde ve diğer bölümlerindeki noktalar arasındaki toplam yoğunluk (intensity) farkı, LiDAR nokta bulutlarının sınıflandırımasında kullanılmaktadır (Lu vd. 2014).

Bienert vd. (2018) tarafında sunulan çalışmada, mobil LTS (MLS) verilerinin standart orman envanter parametrelerinin belirlenmesi ve tepe boylarının analizinde uygunluğu araştırılmıştır. Özellikle, çokölçülü MLS veri alımının yersel TLS veri alımına kıyasla avantaj ve dezavantajları tartışıımıştır.

Yersel LTS verilerinden belirli tek ağaç özelliğinin örneğin, göğüs seviyesinde gövde çapı, ağaç boyu, tepe yüksekliği ve tepe genişliğinin belirlenmesi üzerine çalışmalar ortaya koyulmuştur (Özdemir 2013).

Yoğun nokta bulutu sağlayan yersel LTS, mobil el-tipi LTS sistemleri ile karşılaştırıldığında, EML sistemleri yersel LTS'ye yakın doğrulukta ve yoğunlukta veriler üretmektedir. Bunun yanında ucuz sistemler olması ve kolay taşınabilir özelliğiyle ormancılık ölçmelerinde kullanılmaya başlanmıştır (Cabo vd. 2018, Vatandaşlar ve Zeybek 2020).

Bauwens vd. (2016), farklı orman türlerinde ve yapılarında çeşitli meşçere parametrelerinin tahmini için EML ve yersel TLS yaklaşımlarını değerlendirmiş ve karşılaştırmıştır. Orman yapısı yanında topoğrafik etki de analiz edilmiştir. Çalışma alanlarında aynı LiDAR tarama protokolleri, EML için bir epok ölçü ve TLS için iki epok ölçü (tekli veya çoklu tarama yaklaşımı) yapılmışır.

Orman ölçümleri için KırmızıYeşilMavi-Derinlik (RGB-D) sensörleri ile birlikte eşzamanlı konumlandırma ve haritalama (SLAM) uygulamaları da kullanılmaktadır. Tomaštík vd. (2017) tarafından, Google Tango teknolojisi kullanılarak 3B nokta bulutu oluşturulan çalışma sunulmuştur. Ağaçların çap, konum ve mesafelerinin doğruluğu, yersel fotogrametri ve yersel LTS ile karşılaştırılmış ancak doğruluklarının yersel LTS'ye kıyasla daha düşük olduğu belirtilmiştir.

Hyyppä vd. (2020), saha envanteri referans verisinin toplanmasında operasyonel gereksinimleri karşılamak için yeterli doğruluk seviyesinde olan mobil sırt çantası entegreli lazer tarama sistemlerini kullanarak ağaç gövdesi tespiti ve hacim tahmini için bir yöntem geliştirmişlerdir. Sonuç olarak, türetilmiş gövde eğrileri ve ağaç boyu kullanılarak, düşük ve orta yoğunluktaki kuzey orman arazilerindeki ağaçlar için gövde hacmini tahmin etmişlerdir. Özellikle, gövde hacim tahminini, yersel LTS ile kıyasladıklarında $\% 10$ ortalama hata ile elde ettiklerini belirtmektedirler.

Sınıflandırma işlemleri, farklı disiplinler için de elde edilmiş nokta bulutlarından objelerin tespiti ve sınıflandırılması gibi temel problemler arasında yer almaktadır. Bununla ilgili literatürde, topoğrafik 3B nokta bulutlarını sınıflandıııması için çok ölçekli boyutsallık analizi ve noktalar arasındaki geometrik 
özelliklerden yararlanılarak uygulanan sınıflandırma teknikleri bulunmaktadır (Brodu ve Lague 2012).

Yoğun verilerin elde edilmesi detaylı ağaç parametrelerini sağlarken veri yönetiminde zorluklarla karşılaşılır. Bunun için tek ağaç parametrelerinin hesaplanmasında gövdeyi temsil eden noktaların tespiti önemli bir konudur. Bu çalışmanın önemi, EML nokta bulutu verilerinden ağaç tespiti algoritmasının geliştirilmesi ve gürültülü nokta bulutundan güvenilir seviyede bilgi çıkarılmasıdır. Bunun yanında ağaç gövde noktalarının tek ağaç bazında farklı algoritma ve modelleme yöntemleri ile test edilerek manuel çıkarımlarla karşılaştırılmıştır. Ayrıca EML sisteminin mesafeye bağı farklı yoğunlukta nokta bulutları üzerinde test edilerek yoğunluk seviyelerinin algoritmalar üzerine etkisi de araştırılmıştır.

\section{MATERYAL VE YÖNTEM}

Nokta bulutu yapısındaki verilerin nokta özelliklerine göre olası kümelendirilmesi için farklı yöntemler bulunmaktadır. Bu yöntemlerden, istatistiksel olarak yaygın kullanılan, lojistik regresyon, doğrusal ayrıştırma analizi, rastgele orman ve destek vektör makineleri bu uygulamada kullanılmıştır.

Sınıflandırma analizinde, verilerin komşuluk ilişkisine bağı kovaryans matrislerinden üretilen özdeğer ve özvektörler yardımıyla geometrik özellikleri türetilmiştir. Sınıflandırma ikili sistem yani nokta bulutundaki her bir nokta ya gövdeyi temsil etmektedir (1. grup) ya da gövde olmayan noktayı (2. grup) temsil etmektedir. Nokta bulutları içindeki, noktaların uzaklık ve kovaryans karakteristiklerinin benzerlik ölçütleri sınıflandırmanın yapılmasına olanak sağlamaktadır. Bu sayede benzer özelliği içeren noktalar aynı sınıfa atanmaktadır.

\section{Çalışma Alanı}

Çalışma alanı Trabzon il sınırları içinde ve $40^{\circ} 33^{\prime}$ $41^{\circ} 07^{\prime}$ Kuzey enlemleri ile $37^{\circ} 07^{\prime}-40^{\circ} 30^{\prime}$ Doğu boylamları arasında yer almaktadır. Deniz seviyesinden yüksekliği yaklaşık 37 m'dir. Bölgenin iklimi, tipik Karadeniz ikliminin özelliklerine sahiptir. Yıllık toplam yağış $760 \mathrm{~mm}$, ortalama sıcaklık ise 14.6 ${ }^{\circ} C^{\prime}$ dir (MGM 2019). Topoğrafya oldukça dağlık ve engebeli bir yapıdadır. Orman alanlarında asli ağaç türü olarak; doğu ladini (Picea orientalis), sarıçam (Pinus sylvestris), doğu kayını (Fagus orientalis), kızılağaç türleri (Alnus sp.) ve doğu gürgeni (Carpinus orientalis) bulunmaktadır. Ziraat alanlarında ise genellikle fındık ve kısmen çay tarımı yapılmaktadır. Kıyıya paralel uzanan dağlar yükseldikçe mera ekosistemi ve yaylalara rastlanmaktadır. Kentleşme ise daha çok kıyı kesimlerde görülmektedir. Kent nüfusu 250000 olarak bildirilmektedir (Eren vd. 2018). Inceleme alanından seçilen ağaç türü Sahil çamıdır. 1.30 m'deki göğüs çapı 47.5 cm'dir. Arazi eğimi ise yaklaşık \%10 civarındadır.

\section{Veri Toplama}

Veri toplama işlemi GeoSLAM ZEB-REVO marka ve model el-tipi mobil LiDAR cihazı ile yapılmıştır. Batarya, veri depolama ve işleme birimlerinin boyutları taşınabilir ağırlıktadır. Motorla çalışan tarayıcı birimi tarama bölümünü oluşturur ve motor hareketi sayesinde sistem 3B-eş zamanlı lokalizasyon ve haritalama (SLAM) algoritmalarıyla yoğun $3 \mathrm{~B}$ verilerinin üretilmesini sağlamaktadır (Sammartano ve Spanò 2018). Bu cihaz sayesinde araştırma alanına ait üç boyutlu yoğun koordinat bilgileri temin edilebilmektedir. Veri toplama, temel olarak kapalı alanlar içinde $0.60-30 \mathrm{~m}$ ve açık alanlarda ise $0.60-15 \mathrm{~m}$ menzilleri arasında, saniyede 43,200sinyal gönderme oranı ile gerçekleşmektedir (Geo-SLAM 2019). Bu çalışmada kullanılan GeoSLAM ZEB-REVO tarama cihazına ait özellikler Çizelge 1'de verilmiştir. 
Çizelge 1. GeoSLAM ZEB-REVO teknik özellikleri

\begin{tabular}{ll}
\hline \multicolumn{1}{c}{ Özellik } & Parametre değerleri \\
\hline Maksimum tarama mesafesi & İç mekan: $30 \mathrm{~m}$ \\
Lazer tarayıcı & Dış Mekan: $15-20 \mathrm{~m}$ \\
Lazer ölçme prensibi & 1 adet \\
Tarama ölçme veri oranı & Uçuş zamanlı (ToF) \\
Tarama çözünürlüğüu & 43200 nokta/sn \\
Lazer dalga boyu & Yatay:0.625 \\
Bağıl konum doğruluğu & Düşey: $1.8^{\circ}$ \\
Mutlak konum doğruluğu & $905 \mathrm{~nm}$ \\
Toplam sistem ağırlığı & $2-3 \mathrm{~cm}$ \\
\hline
\end{tabular}

Cihaz el-tipi bir cihaz olmakla beraber farklı platformlara yerleştirilerek de kullanılmaktadır. Ancak bu çalışmada el ile tutulup orman içerisinde yürüyerek veri toplanmıştır. Veri toplama aşamasında herhangi bir planlama ve küresel konumlandırma sistemi (GNSS)'ne ihtiyaç duyulmamaktadır. SLAM algoritmaları ile veriler ölçüm sonrasında arazide işlenerek nokta bulutları, bütün ve tek las dosya formatında çıktı olarak alınmıştır.

\section{Veri Ön İşleme}

Nokta bulutları, milyonlarca noktaya ait koordinat verisinin oluşturduğu yoğun veri formatıdır. Kestirilecek parametrelerin doğruluğunun arttırılması için, işlemlere başlamadan önce nokta bulutlarının filtrelenmesi hem performansı arttırır hem de doğruluk kriterlerini yükseltir. Bu veri düzeltme işlemleri uygulandıktan sonra daha tutarlı sonuçlar da elde edilmektedir.

Veri ön işleme aşamasında, uyuşumsuz ve gürültülü noktalar nokta bulutlarından temizlenir. Saçılıma sahip noktaların belirli yüzeye indirgenmesi ölçü hatalarını minimize eder. Bunun için istatistiksel gürültü silme (SOR) algoritması ve nokta bulutlarının saçılımlarını engellemek için kayan en küçük kareler yüzey (MLS) algoritması uygulanmıştır. Bu uygulamalar CloudCompare açık kaynak yazılımında uygulanmıştır (CloudCompare 2013).

SOR, her bir noktanın komşu noktalarla olan istatistiksel ilişki değerlerine göre aykırı veya uyuşumsuz noktaların tespiti ve filtrelenmesinde kullanılmıştır (Rusu 2009). Bu noktaların oluşum sebepleri yaygın olarak, yüzey normalleri, yüzey eğriselliği, yüzey geometrisi, yüzeyin oluştuğu materyalden veya lazer tarama sistemlerinden kaynaklı hatalı gözlemlerdir. Ayrıca, bu hatalı noktalar, 3B modelleme süreçlerinde model ve parametre kestirimlerinde de hataya sebep olabilmektedir.

SOR algoritması, her noktanın k-en yakın komşuluk (k-nn) değerlerine göre belirli komşu noktasıyla istatistiksel bir analiz yaparak ve belirli sapma limitlerinde olmayan noktaları tespit ederek bu noktaların temizlenmesini sağlamıştır.

Filtreleme ve düzenleme işleminde sonra normalizasyon işlemleriyle süreç devam etmektedir. Nokta bulutlarının yer ve yer üzeri olarak sınıflandırılması hem kesitlerin doğru yükseklikten hem de ağaç yüksekliğinin kestirilmesi için gereklidir. Bez simülasyonu algoritması yer ve yer üzeri noktaların sınıflandırılmasında kullanılmıştır (Zhang vd. 2016). Nokta bulutu (P) içindeki sınıflandırma değeri ( $C$, yer=2, yer üzeri=1) her bir noktanın $p_{i}=\left\{x_{i}, y_{i}, z_{i}\right\} \quad z_{i} \quad$ değerleri içindeki maksimum değer ağaç yüksekliğini vermektedir (Eşitlik (1)).

$h=\max \left(\forall z_{i} \in p_{i} \& C \leftrightarrow 1\right)$

Yer üzeri noktalar yer noktalarından ters mesafe ağırlıklandırma (IDW) enterpolasyonu ile komşuluk sayısı 6 ve 2. dereceden elde edilmiş sayısal arazi modeline olan mesafeleri ile normalizasyon değerleri hesaplanmıştır (Şekil 1). 

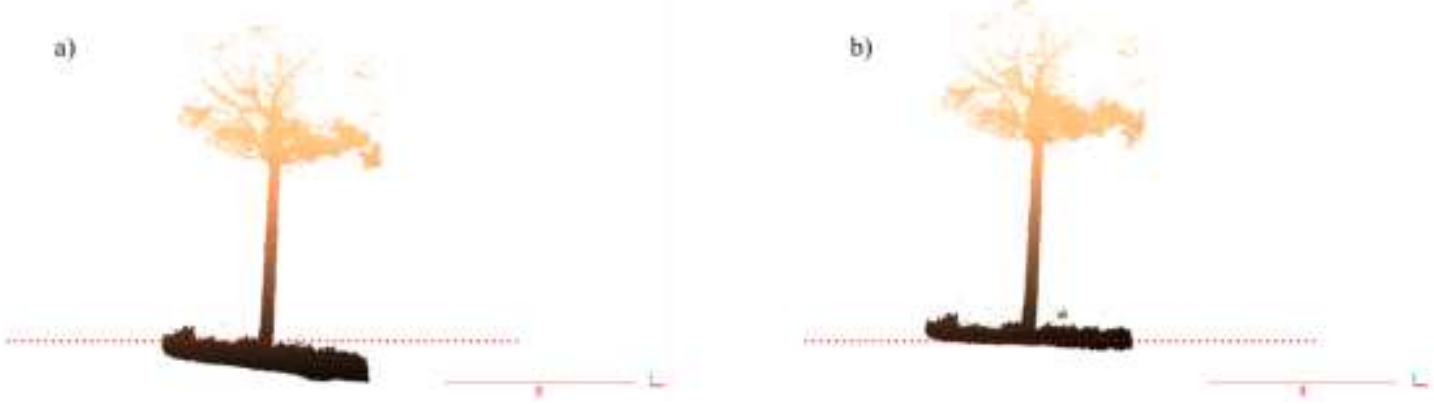

Şekil 1. a) normalizasyon öncesi nokta bulutları, b) normalizasyon sonrası nokta bulutları

Manuel karşılaştırma verisinin oluşturulması için ise kesitlerin hazırlanması bu aşamada gerçekleşmektedir. Önerilen algoritmanın yeterli doğruluğa erişip erişmediğinin kontrolü 1 metre aralıklarla ağaç yer üzeri noktaları kesitlerine göre yapılmıştır. Her bir kesit üzerinden en küçük kareler kestirimi (EKK) ile silindir uygulaması 3DReshaper programı (3DReshaper 2020) kullanılarak yapılmıştır.

Sınıflandırıcı yöntemlerinin eğitim örnekleri için 10 farklı değişken kullanılmıştır. Bunlar, komşuluk değerlerinin varyanslarıyla ilgili geometrik karakteristiği ortaya koyan özelliklerdir (Pessoa vd. 2019).

\section{Lojistik Regresyon}

Lojistik regresyon (bayes tabanlı bayesGLM) analiz işleminde nokta bulutlarında ayrılmak istenen sınıf sayısının önceden bilinmesi gerekir (Ghatak 2017). Bu parametreden yola çıkarak ayırma modeli ortaya koyulur. Elde edilen model ile farklı nokta bulutları, özelliklerin benzerlik değerlerine göre sınıflandırıır. Lojistik regresyon analizinde temel amaç az değişken kullanarak en iyi uyuma sahip modeli değişkenlere göre tespit etmektir. Lojistik regresyonun diğer basit regresyonlardan ayıran önemli özellik kategorik verilerden model oluşturup sonucun ikili veya çoklu olmasıdır. Bu çalışmada lojistik regresyonun seçilmesindeki temel sebep ise nokta bulutlarının gövde (1) ve gövde olmayan (0) aralığında ikili sistemin tanımlanmasıdır.
Lojistik regresyonda sınıflandırmanın veya bağımlı değişkenlerin kategorik olduğu bir regresyon modeli kurulur. Gövde veya gövde olmayan noktaların sınıflandırılması bağımlı değişkeni, noktaların geometrik özellikleri de bağımsız değişkenleri ifade eder. Model, lojistik fonksiyonu $f(x)=\frac{1}{1+e^{-x}}$ kullanarak, kategorik bağımlı değişkenin tahmin değişkenlerine dayalı olasııı̆ını kestirir (Ghatak 2017, Pal 2017). Lojistik regresyonu tanımlamak için Y, ikili sınıflandırma ve $\operatorname{Pr}(Y=1 \mid X=x)$ modeli varsayılmalıdır. Olasılığın logit dönüşümüne (sigmoidal veya lojistik fonksiyonun tersi) dayanan lojistik regresyon modeli (aralık sınırsızdır), kestirim parametrelerine doğrusal kombinasyonuna eşitlemek Eşitlik (2)'deki gibi

$$
\ln \frac{p(x)}{1-p(x)}=\beta_{0}+x \beta
$$

ve $p(x)$ 'in hesaplanması Eşitlik (3)'teki gibi,

$$
p(x)=\frac{1}{1+e^{-\left(\beta_{0}+x \beta\right)}}
$$

olacaktır.

Sezgisel olarak, 0 ile 1 arasında sınırlanmış nokta sınıfları üzerinde sürekli bir olasılık dağılımı sağlamak için sonuç değişkenine bir dönüşüm uygulanmalıdır; bu dönüşüm, ' $x$ ' log oranlarının logit ile bölünmesine karşıllı gelen "lojistik" veya "sigmoid" fonksiyonu ile sağlanır (Şekil 2) (Kirasich vd. 2018). 


\section{Lojistik fonksiyon}

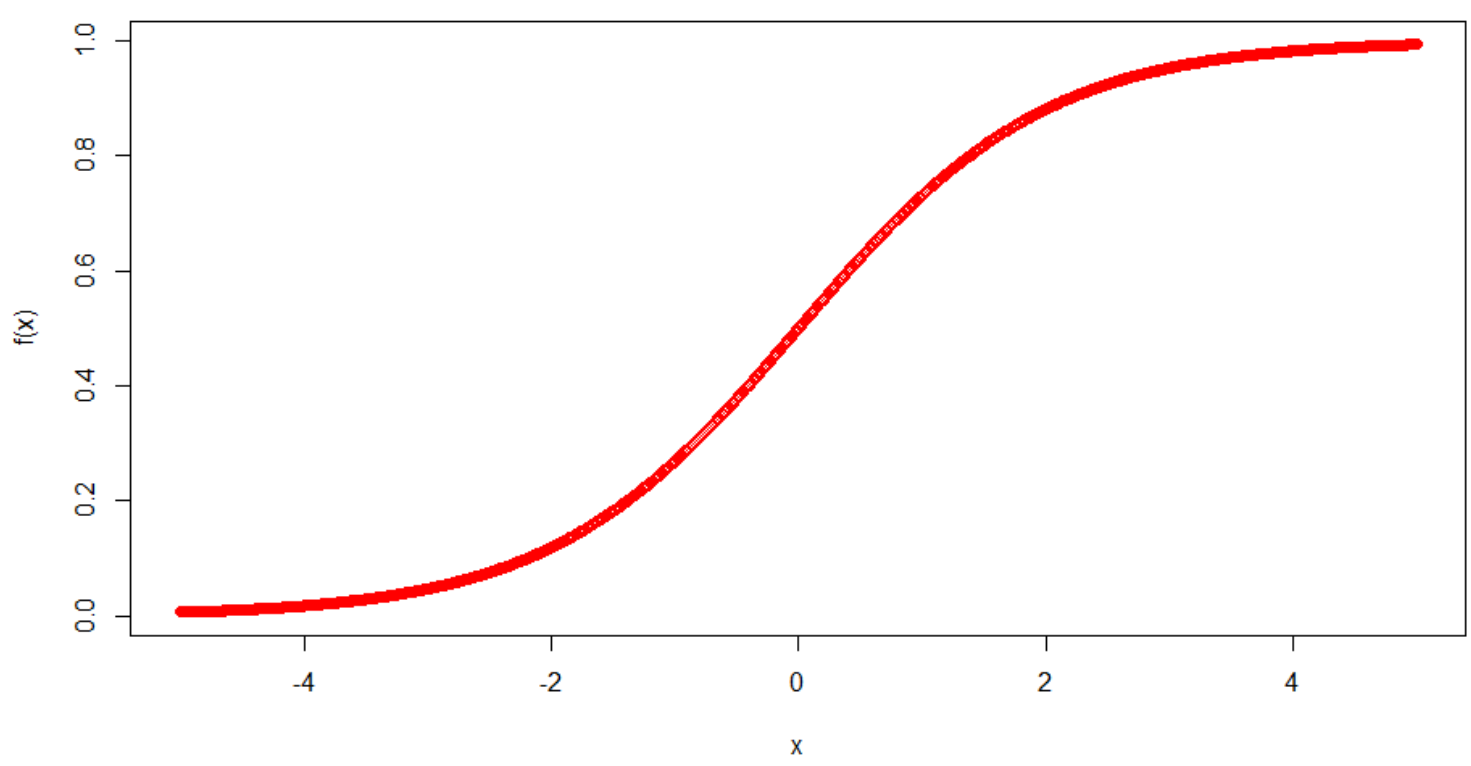

Şekil 2. Lojistik fonksiyon

ikili bir sınıflandırma için, lojistik regresyon modeli, girdi özelliklerinin doğrusal kombinasyonları ve ilgili parametrelere karşılık gelen bir ağırlık (w) ile sapma parametresinin (b) toplanmasılyla ifade edilebilir (Eşitlik (4)).

$$
\begin{aligned}
& p\left(y^{i}=1 \mid x^{i}, w\right)=1-\frac{1}{1+\exp ^{\left(w^{T} x^{i}+b\right)}} \\
& p\left(y^{i}=0 \mid x^{i}, w\right)=1-\frac{1}{1+\exp ^{\left(w^{T} x^{i}+b\right)}}
\end{aligned}
$$

\section{Doğrusal Ayrıştırma Analizi}

Noktalara ait özellik sınıflarının iyi ayrıldığı durumlarda, lojistik regresyon modeli için alternatif bir sınıflandırma tekniğidir. Özellik sınıflarının iyi ayrılmış olmasına rağmen sonuç sınıflandırmalar beklenildiği kalitede değilse, bu sonuç, lojistik regresyona ait kararsız parametre tahminlerinin varlığını göstermektedir. Bu durum lojistik regresyonda, güven aralıklarının geniş olduğunu ve tahminlerin bir örnekten farklı örneklere geçişlerde oldukça farklı oranlarda değişebileceğini göstermektedir (Lesmeister 2015). Doğrusal ayrıştırma analizi bu problemden etkilenmemektedir. Örneklem sayısının küçük olduğu durumlarda ve bağımsız değişken sınıflarının her biri yaklaşık olarak normal dağılımda olduğunda, doğrusal ayrıştırma analizi lojistik regresyon modeline göre daha kararlı olmaktadır.

Bir p-boyutlu rastgele değişken $X^{\prime}$ in çok değişkenli bir Gauss dağılımına sahip olduğunda $X \square N(\mu, \Sigma)$ şeklinde gösterilir. Burada $E(X)=\mu, X^{\prime}$ in (p bileşenli bir vektör) ortalaması ve $\operatorname{Cov}(X)=\Sigma$, X'in $p \times p$ kovaryans matrisini temsil eder. Çok değişkenli Gauss yoğunluğu ise Eşitlik (5)'teki gibidir.

$$
f(x)=\frac{1}{(2 \pi)^{p / 2}|\Sigma|^{1 / 2}} \exp \left(-\frac{1}{2}(x-\mu)^{T} \Sigma^{-1}(x-\mu)\right)
$$

Bu çalışmada, LDA sınıflandırıcısını birden çok tahmin edici parametreye göre genişletilmiştir. Bunun için, $X=\left(X_{1}, X_{2}, \ldots, X_{p}\right)$, sınıflarına özgü bir ortalama vektör ve ortak bir kovaryans matrisinin çok değişkenli bir Gauss (veya çok değişkenli normal) dağılımından belirlendiği varsayllır (Kuhn ve Johnson 2013). Gözlemlerin yoğunluk değerlerine göre sınıflandırılması, k gözleminin 
$\delta_{k}(x)=x^{T} \Sigma^{-1} \mu_{k}^{T}-\frac{1}{2} \mu_{k}^{T} \Sigma^{-1} \mu_{k}+\log \pi_{k}$

Bayes sınıflandırıcısının en büyük değeriyle sınıf ataması gerçekleştirilir. Gözlemlerin dağılımlarına bağlı sınıfların her biri için olasılığın \%95'ini içeren bölgeler elips veya daire ile temsil edilir (James vd. 2013).

\section{Rastgele Orman}

Rastgele Orman (RF) sınıflandırıcısı, ağaç sınıflandırıcılarının bir koleksiyonu olarak tanımlanır (Akar ve Güngör 2015, Breiman 2001, Kirasich vd. 2018). Sınıflandırma işlemi için kullanıcı iki parametreyi belirler. Bu parametreler sınıflandırma için kullanılacak ağaç sayısı ve düğümlerin ayrılmasında kullanılan değişken sayısıdır. Rastgele Orman, bir tahmin yaparken yaprak düğümlerinde ortalama (regresyon) veya çoğunluk oylarını (sınıflandırma) hesaplamak için birden fazla ağaç kullanır (Ghatak 2017). Karar ağaçları, üst düğümün bir dizi karar düğümünde ayrım dügümüne veya karar düğümüne ulaşana kadar özyinelemeli olarak bölünmüş olan ağacın kökü olduğu düşünülen ağaç benzeri bir yapıdan oluşur. Her düğümde hangi özelliğin bölüneceğini belirlemek için entropi hesaplanır. Entropi, altküme verilerinin homojenliğini ölçer; entropi bire eşitse, sınıf etiketleri eşit olarak bölünürken sıfır entropisi örneklemin tamamen homojen olduğu anlamına gelir. Bu çalışmada olduğu gibi yalnızca ikili sınıflandırma durumunda, bölünme sınıf etiketlerinin 1 veya 0 olmasıyla sonuçlanır, entropi bu durumda sıfır olacaktır. Benzer şekilde, sınıfların yarısı 1 veya 0 ise, daha yüksek bir 1 entropisi gözlenmektedir (Şekil 3).

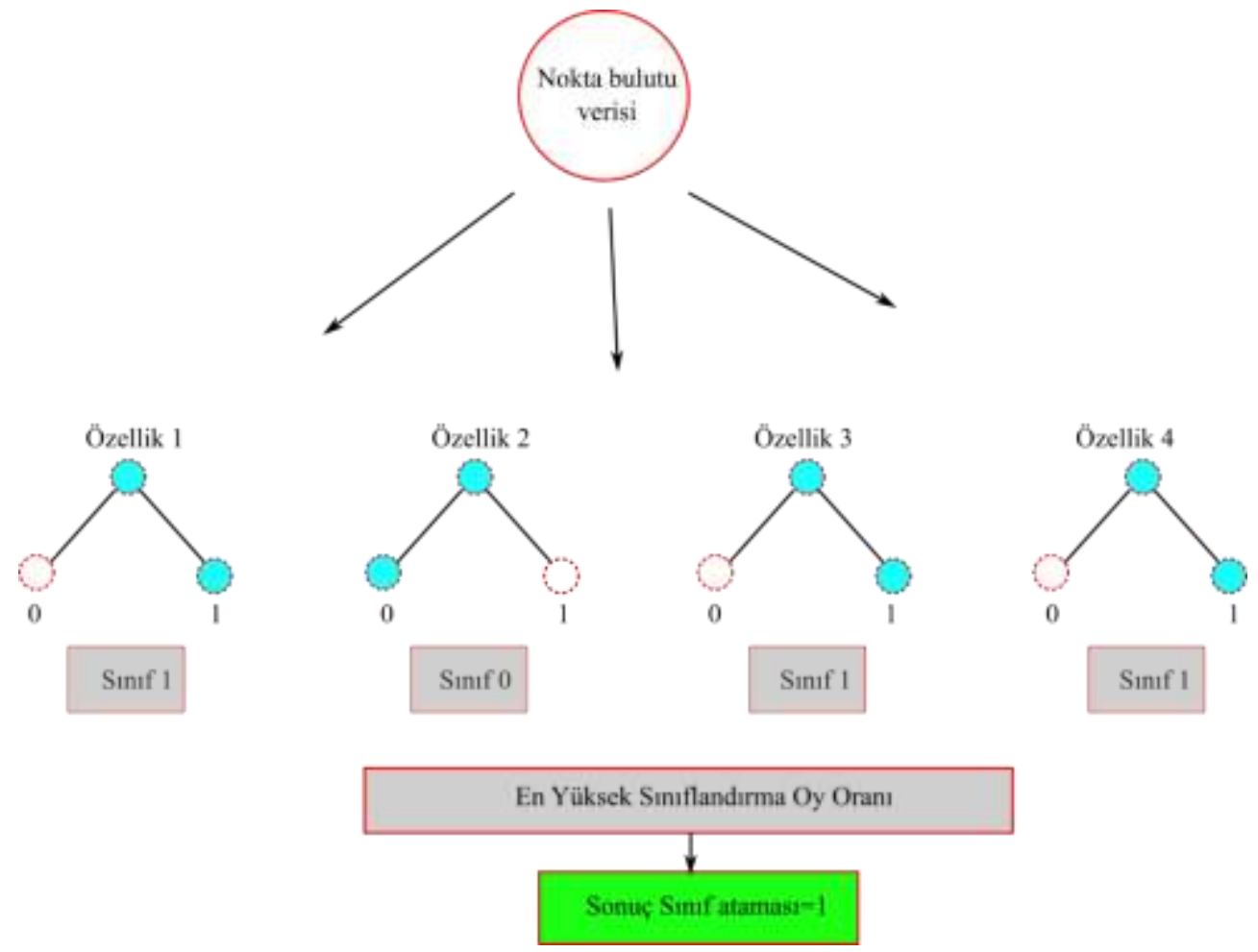

Şekil 3. Rastgele Orman karar ağacının ikili sınıflandırmada 4 özellikli veri için mimari örneği

Rastgele orman sınıflandırıcısının özellik sayısı m ve ağaç sayısı n olmak üzere iki parametresi bulunur (Breiman 2001). \%70'lik kısmı ayrılmıştır. Kestirim dışında kullanılan \%30'luk doğrulama verileri ise model hatasının çapraz doğrulaması için kullanılmıştır.

Rastgele orman sınıflandırıcısının uygulanmasında ilk olarak, veri eğitim örnekleri için veri setinin 


\section{Destek Vektör Makineleri}

Bu bölümde, 1990'larda bilgisayar bilimleri tarafından geliştirilen ve o zamandan bu yana yaygın kullanılan bir sınıflandırma yaklaşımı olan destek vektör makinesi (SVM) açıklanmıştır. Bu çalışmada SVM, iki sınıfın bulunduğu ikili sınıflandırma için tasarlanmıştır. SVM için bir hiper düzlem tanımlanmalıdır ve optimal bir ayırma hiper düzlemi değişkenler arasından kestirilmektedir (Robert I. 2015).

İki boyutta, $a_{0}, a_{1}$ ve $a_{2}$ parametreleri için bir hiper düzlem aşağıdaki denklem (Eşitlik (7)) gibi tanımlanır.

$a_{0}+a_{1} * X_{1}+a_{2} * X_{2}=0$

Tanımlanan hiper düzlemi, herhangi bir $X=$ $\left(X_{1}, X_{2}\right)^{T}$ değişkenleri için hiper düzlemde bir nokta olduğu belirtilir. İki değişkenli sınıflandırma işleminde hiper düzlem basit bir çizgi denklemi olduğu unutulmamalıdır, aslında iki boyutlu bir hiper düzlem olmaktan daha çok bir çizgiyi ifade etmektedir.

Genel hiper düzlemi seçimi, eğitim gözlemlerinden en uzak olan ayırma hiper düzlemi yani maksimum sınırdır (optimal ayırma kenarı olarak da bilinir). Yani, her bir eğitim gözleminden belirli bir ayırma hiper düzlemine olan (dik) mesafe hesaplanır; bu yakın mesafe, gözlemlerden hiper düzleme olan minimum mesafedir ve kenar olarak bilinir.

Her bir gözlemin sınıf değeri ikili sınıflandırmada koşul denkleminde belirlenen hiper düzlem denkleminin pozitif veya negatif tarafında olmasıdır. Bu da eğitimde sınıflandırılmış verilerinden türetilen hiper düzlem denklemi ile sağlanır. Belirlenen hiper düzlem denklemine göre sınıflandırma değerleri koşul denklemine (Eşitlik (8)) göre sınanır ve sınıflandırma işlemi tamamlanır.

$y_{i}\left(a_{0}+a_{1} * X_{1}+a_{2} * X_{2}+\ldots+a_{p} * X_{i}\right) \geq$ Maksimize $\forall i=1 \ldots, n$ burada $y_{i}$ sınıfları $(0,1), p$ boyutu, $n$ gözlem sayısını ifade eder.

Belirli çekirdek fonksiyonları kullanılarak doğrusal olmayan ayrılabilir sınıf durumlarının özellik uzay alanını genişlettikten sonra, destek vektör makinesinin kullanılmasına imkan sağlanır. Buradaki temel amaç doğrusal olarak ayrılamayan sınıfları sınıflandırmaktır ve sadece her bir gözlem için değil, bu süreçte ayrıca gözlemlerin iç bölümleri de önemlidir. Doğrusal çekirdek işlevi, polinom ve radyal çekirdekler gibi çok daha esnek karar sınırlarına kadar genişletilebilir.

\section{Optimizasyon}

Verilerin sınıflandırma sonrasında daha da iyileştirilmesi, uyuşumsuz ve saçılmış verilerden daha iyi filtrelenmesi için iki aşamalı optimizasyon önerilmiştir. Bunun için ilk işlem, Medyan mutlak sapması (MAD) mutlak sapmaları hesaplanır (Eşitlik (9)).

$M A D=c \cdot \operatorname{median}\left(\left|x_{i}-\tilde{x}\right|\right)$

Burada $c_{1}=1.4826$, kestirimin tutarlı hale getirilmesinde kullanılan bir düzeltme faktörüdür (Wilcox 2010), $x$ gözlemleri, $\tilde{x}$ gözlemlerin ortalamasını temsil etmektedir.

Belirlenen sınıfların normal tutarlılık içinde olup olmadıkları MAD ile test edilir. Robust (sağlam) istatistik, geniş ölçüde normal dağılmamış olasılık dağılımlarından alınan veriler için iyi performansa sahip istatistiklerdir ve standart ortalama/standart sapma kombinasyonundan farklı olarak MAD, aykırı değerlerin varlığına duyarlı değildir. Kesit ortalama değerlerinden elde edilen mesafeler MAD değeri ile karşılaştırılır. Bu karşılaştırmada belirli limit değerini geçen kesitler için ikinci aşamanın gerçekleştirilmesi gerekir.

İinci aşama ise, Gauss karışım modellemesi (GMM, Gaussian mixture model) algoritmasıdır. Burada $X=\left\{x_{1}, x_{2} \ldots x_{n}\right\} \mathrm{n}$ bağımsız aynı şekilde dağılmış gözlemin bir örneği varsayılır. Her gözlemin dağııımı, 
aşağıdaki formülde $\mathrm{G}$ bileşenlerinin sonlu bir karışım modeli yoluyla bir olasılık yoğunluk fonksiyonu ile belirtilir (Eşitlik (10)) (Bishop 2006).

$f\left(x_{i}, \Psi\right)=\sum_{k=1}^{G} \pi_{k} f_{k}\left(x_{i}, \theta_{k}\right)$

Burada, $\Psi=\left\{\pi_{1}, \ldots, \pi_{G-1}, \theta_{1}, \ldots, \theta_{G}\right\} \quad$ karışım modelinin parametrelerini ifade eder. $f_{k}\left(x_{i}, \theta_{k}\right)$, $x_{i}$ gözleminin $\theta_{k}$ vektör parametresi için $k$ bileşeninin yoğunluğudur. $\pi_{k}$, ise karışım modelinin ağılığıdır. $G$, karışım bileşeni sayısıdır.

\section{Doğruluk Kriterleri}

İstatistiksel sınıflandırma sonrasında, hata matrisi olarak da bilinen karışım matrisi, bir algoritmanın performansının gözetilmesini sağlar (Yener vd. 2006). Matrisin her satırı, model tahmininin her bir sınıftaki örneklerini temsil eder, her sütun ise referans veri sınıfının örneklerini temsil etmektedir (Çizelge 2).

Çizelge 2. Karışım matrisi

\begin{tabular}{llll}
\hline & & Referans \\
\hline \multirow{3}{c}{} & & Gövde & Gövde değil \\
$\frac{c}{\sqrt{\sigma}}$ & Gövde & TP & FP \\
$\vdash$ & Gövde değil & FN & TN \\
\hline
\end{tabular}

\section{a)}

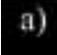

Karışım matrisi üzerinden hesaplanan genel doğruluk kriteri farklı sınıflandırmalar için karşılaştırma kriteri olarak hesaplanmıştır. Aşağıda genel doğruluk kriteri için eşitlik verilmiştir.

GenelDogruluk $=\frac{T P+T N}{T P+F P+F N+T N}$

\section{BULGULAR ve TARTIŞMA}

İstatistiksel sınıflandırma yöntemlerinin etkinliğini değerlendirmek için EML nokta bulutu verisi içinden manuel olarak bir adet Sahil çamı seçilmiştir. Lojistik regresyon, doğrusal ayrıştırma, rastgele orman ve destek vektör makineleri ile nokta bulutları gövde ve gövde olmayan sınıflar olarak ayrılmış ve nokta bulutları formatında sınıflandırma bölümünde belirli sınıfa atanmışlardır. Son olarak, uygulanan sınıflandırma algoritmaları sonrasında sonuçların iyileştirilmesi için GMM sınıflandırıcısı iyileştirme amaçlı uygulanmıştır.

Nokta bulutlarının yer ve yer üzeri olarak CSF ile ayrıldıktan sonra 60,634 nokta yer noktası, 367,908 nokta yer üzeri nokta olarak sınıflandırılmıştır (Şekil 4). Normalizasyon sonrasında yer üzeri noktalar yer noktalarına Öklid mesafesi hesaplanarak ağaç yüksekliği tespit edilmiştir.

\section{b)}

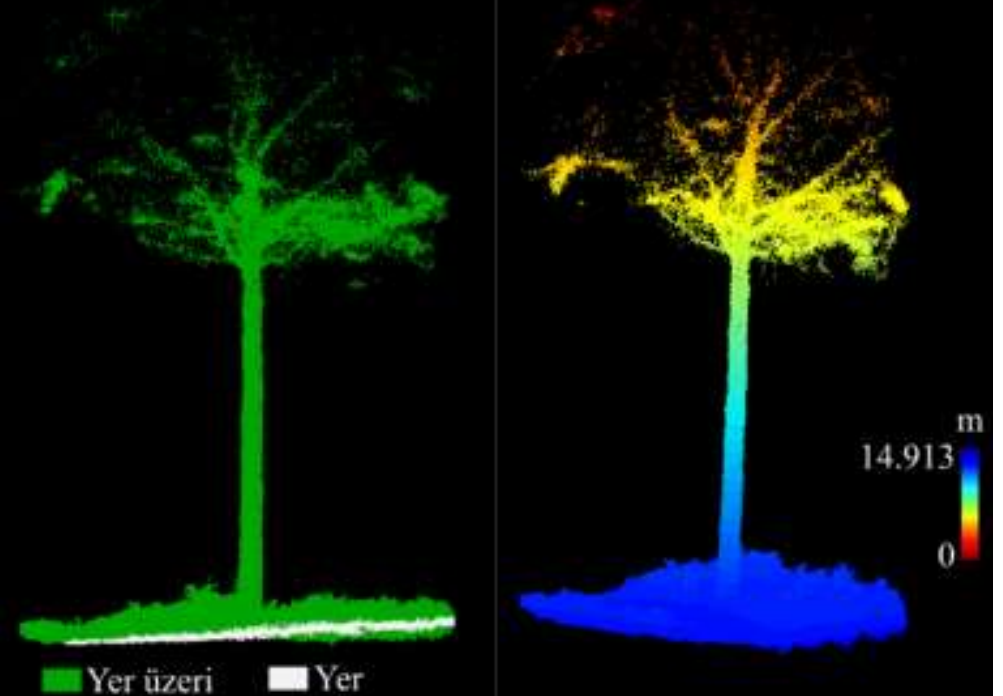

Şekil 4. a) Yer ve yer üzeri noktaların CSF algoritması ile sınıflandırılması, b) yer üzeri noktaların yer noktalarına mesafesi 
Nokta bulutları filtreleme ve uyuşumsuz ölçü silinmesi işlemi sonrasında yer üzeri noktalardan otomatik olarak 1 metre aralıklarla kesitler alınmıştır. Bu kesitler üzerine EKK uygulanarak silindir kestirimi yapılmıştır. EKK yöntemi uyuşumsuz ölçme noktalara duyarlı olduğundan kesitlerdeki gövde haricindeki diğer noktalar manuel olarak temizlenmiştir. Silindir model ile gövde kesit noktaları arasındaki sapmalar Şekil 5'de verildiği gibi $\% 80$ 'lik bölümü $\pm 5 \mathrm{~cm}$ sapmalara sahiptir. Standart sapma değerleri ağaçların son kesitlerinde arttığı tespit edilmiştir (Şekil 5j). Bu durumun temel sebebi ise ağacın dip kısmı (kütük) nayloit, gövdesi silindirik, uç kısmının ise konik şekle daha çok benzemesidir.

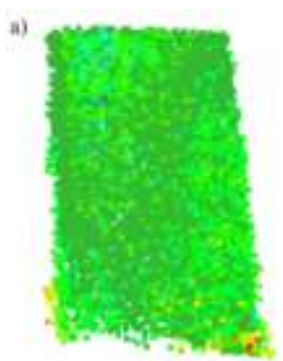

c)

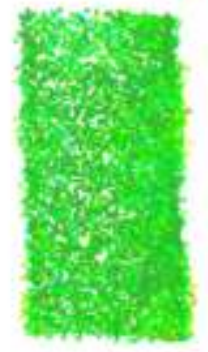

e)

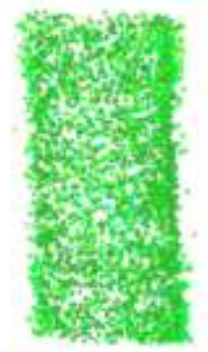

5)

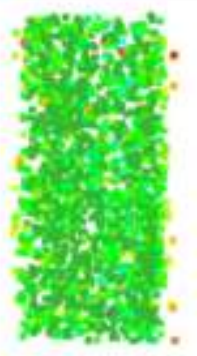

i)

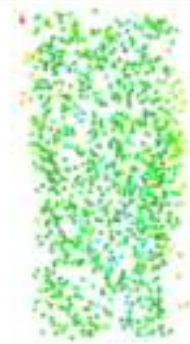

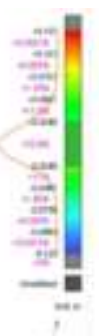

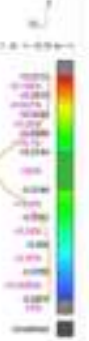

d)
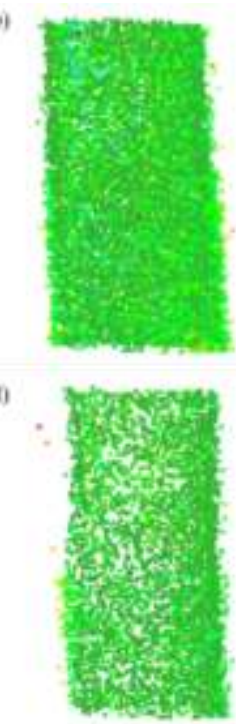

f)

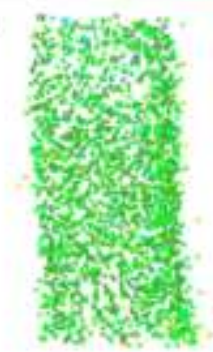

h)

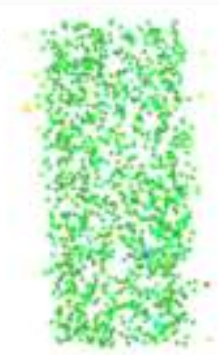

j)

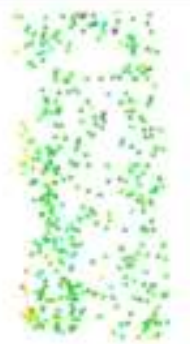

Şekil 5. Kesitlerin zeminden maksimum ağaç yüksekliğine noktaların silindir modelden sapmaları (a-j sırasıyla 1-10. Kesitler) 
Sınıflandırıcı modellerinin eğitim örnekleri için 10 farklı değişken kullanılmıştır. Bunlar, yüzey normalleri $\left(\mathrm{n}_{\mathrm{x}}, \mathrm{n}_{\mathrm{y}}, \mathrm{n}_{z}\right)$, omnivaryans, eğrilik, düzlemsellik, doğrusallık, yüzey varyansı, anisotropi, düşeysellik özellikleridir (Weinmann 2016). Uygulanan algoritmaların sınıflandırma sonrasındaki performans değerleri Çizelge 3 'teki gibi elde edilmiştir.

Çizelge 3. Doğruluk ve performans kriterleri

\begin{tabular}{|c|c|c|c|c|}
\hline Sınıflandırıcı & $\begin{array}{c}\text { Ham veri } \\
\text { SOR ve MLS sonrası }\end{array}$ & $\begin{array}{c}\text { Doğru sınıflandırılan nokta sayısı } \\
\text { (Optimizasyon sonrası) }\end{array}$ & Genel doğruluk & Hesaplama süresi (sn: saniye) \\
\hline bayesGLM & 435842 & 30365 & 0.924 & $3.78 \mathrm{sn}$ \\
\hline LDA & 435842 & 20926 & 0.904 & $3.33 \mathrm{sn}$ \\
\hline SVM & 435842 & 28646 & 0.922 & $7.75 \mathrm{sn}$ \\
\hline RF & 435842 & 44047 & 0.946 & $43.38 \mathrm{sn}$ \\
\hline
\end{tabular}

Sınıflandırııılara ait elde edilen gövde ve gövde olmayan noktalar Şekil 6'da verilmiştir. modeli olmuştur. Ancak veri işleme performansı diğer sınıflandırıcılara göre daha düşüktür.

Çizelge 3 ve Şekil 6’ya göre yeterli nokta bulutu sağlayan ve doğruluğu yüksek sınıflandırıcı RF

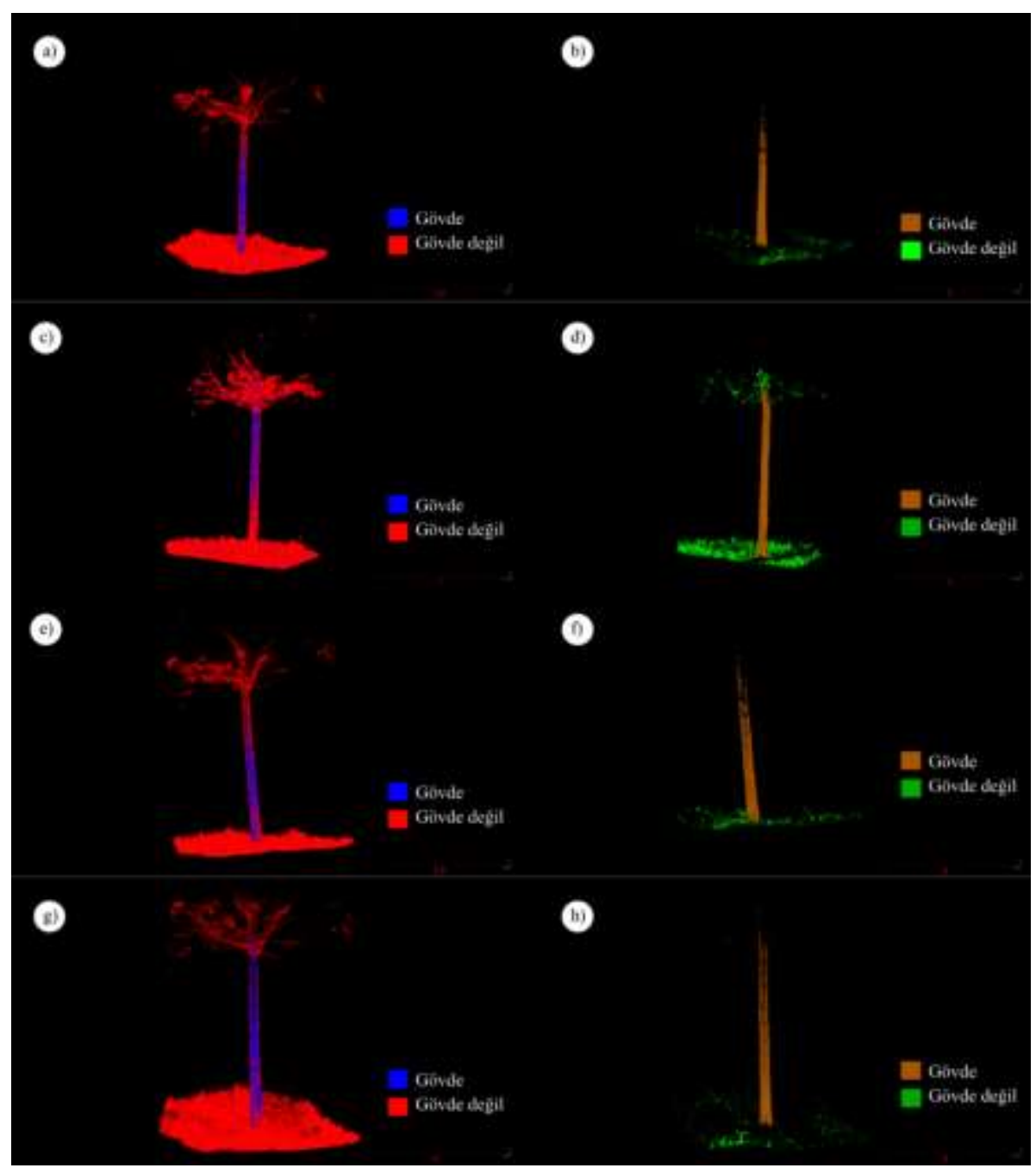

Şekil 6. a) bayesGLM sınıflandırıcısı, b)bayesGLM GMM ile optimize edilmiş nokta bulutu, c) LDA sınıflandırıcısı, d) LDA GMM ile optimize edilmiş nokta bulutu, e) SVM sınıflandırıcıSı, f) SVM GMM ile optimize edilmiş nokta bulutu, g) RF sınıflandırıcıSı, h) RF GMM ile optimize edilmiş nokta bulutu. 
Ağaç yüksekliği $15 \mathrm{~m}$ dolaylarında olsa da gövdeyi temsil eden noktalar $10 \mathrm{~m}$ dolaylarında tespit edilmiştir. Bunun temel sebebi el-tipi mobil LiDAR tarayıcısının etkili mesafesinin kısıtlı olması, yaprak ve dalların gövde görüşünü engellemesidir.

LDA yöntemi gövde bütünlüğünün sağlanmasında ve gövdenin daha yoğun nokta bulutuyla temsil edilerek sınıflandırılmasında başarılı olduğu görülmektedir. Ancak gövde nokta sayısı olarak RF modelinin başarısı daha yüksektir. Elde edilen bulgulara göre RF modelinin gövdeyi temsil eden noktaların tespitinde başarıı olmasına rağmen bazı dal noktalarının da gövde noktası olarak sınıflandırıldığı görülmektedir. Bu noktaların optimizasyonu için GMM etkili filtreleme sağlamıştır. GMM optimizasyonu ikili sınıflandırma yapmaktadır. Eğer nokta bulutlarında ağaçlar tek olarak ayrılamaz veya karmaşık yapıda ise tek ağaç gövdesinin etkili bir şekilde sınıflandırılması için iterasyonlu GMM veya farklı olasılık kestirimleri kullanılmalıdır. Aksi takdirde gövde noktalarına yakın nokta kümeleri varlıklarını sürdürecektir.

Envanter, örnekleme alanlarında ölçülen veriler yardımıyla sağlanmaktadır. Bu çalışmada tek örnek ağaçtan gövdenin çıkarımı ile ilgili bilgiler verilmektedir. Örnekleme (Plot) alanlarının 400-800 $\mathrm{m}^{2}$ arasında değiştiği düşünüldüğünde, bu uygulamanın geliştirilerek ağaçların tek tek ele alınması gerektiği ve bu çalışmada bahsedilen tüm işlemlerin bir örnekleme alanı için oldukça kısa sürede tamamlanabileceğini göstermektedir. Arazi ölçmeleri topoğrafyaya bağı 5 ile 15 dakika dolaylarında sürmektedir. Nokta bulutlarının işlenmesi ise donanıma bağlı olarak değişmektedir.

Çalışmanın uygulanması açısından bakıldığında, özellikle topoğrafyanın ve bitki örtüsünün yoğun ve karmaşık olduğu alanlarda kullanım ve ölçme kolaylıkları sağladığı görülmüştür. Ancak aynı kolaylıklar nokta bulutlarının işlenmesinde mümkün olmamaktadır. Nokta bulutlarının işlenmesinde yoğunluk farkları ve tarama menzilinden kaynaklı veya sistematik hataların var olduğu durumlar göze çarpmaktadır. Bu hataların giderilmesi için robust yöntemlerin uygulanması ve gövde çıkarımının yapılması bu problemlerin çözülmesine katkı sağlamaktadır. Bunun yanında EML sistemlerinin uzun menzilli LiDAR sensörleri, ağaç yükseklik ve tepe noktalarının görüntülenmesinde etkili rol oynamaktadır.

Ağacın göğüs yüksekliğinde çap değerlerinin (DBH) $1.30 \mathrm{~m}$ 'den çıkarılması bu çalışma sonucunda otomatik olarak çıkarılan gövde noktalarında gerçekleştirilebilmektedir. Ancak konu kapsamı içerisinde değerlendirilmediğinden gelecek çalışmalarda otomatik DBH çıkarımları ile ilgili detaylı çalışmalar planlanmaktadır.

Ağaç gövdesinin örnek alanlarında LiDAR nokta bulutlarından çıkarımında rastgele örneklem uzlaşımı (RANSAC) yaygın olarak uygulanmaktadır. Ancak çok karmaşık nokta bulutlarının içinden geometrik yapılarının çıkarımında da yoğunluğa bağlı hatalı sonuçlara sebep olmaktadır (Fritz vd. 2013, Nurunnabi vd. 2017).

Chen vd. (2019) çalışmalarında, orman örneklemindeki ağaç parametrelerini elde etmek için (GNSS sinyallerinin etkisini ortadan kaldırmak) SLAM teknolojisi ile birleştirilmiş kişisel lazer tarama (PLS) ekipmanı kullanmış ve bir poligonal silindir yöntemi kullanılarak ağaçların DBH'ini hesaplamak için bir yöntem önermiştir. Ancak gövdelerin silindirik olmadığı kesitlerdeki sapmalar bu çalışmada gözardı edilmektedir. Bunun yerine gövde noktalarının korunarak parametrelerin kestirilmesi daha doğru sonuçlara erişim imkanı vermektedir.

HMLS'nin orman alanlarında ölçümleri ile yersel LTS'ye göre önemli ölçüde net avantajları vardır (Liang ve ark. 2014). HMLS'nin ölçü ve taşıma kolaylığı ve yersel LTS sistemlerinin nokta bulutlarının birleştirilmesindeki temel sorunlara göre daha üstün özellikler sağlamaktadır. Bununla birlikte arazi ölçmelerinde ölçüler hızlanır ve ekonomik avantajlar sağlanabilir. 
Daha detaylı parametrelerin geometrik veya özniteliksel bilginin temin edilmesinde kamera senkranizasyonlu, sinyal yoğunluk vb. gelişmiş özelliklerin EML sistemlerine entegrasyonu orman envanterinde belirtilen diğer parametrelerin de elde edilmesine olanak sağlayacağı açıktır.

\section{SONUÇ}

Sonuç olarak, farklı istatistiksel sınıflandırıcıların eltipi mobil LiDAR nokta bulutlarından elde edilen tek ağaç gövde ve gövde olmayan noktaların doğruluk performansları araştırılmasına katkı sağlanmıştır. İstatistiksel sınıflandırma algoritmaları ve nokta bulutlarının geometrik özellikleri sayesinde ağacı oluşturan temel kısımlar nokta bulutlarında ikili olarak otomatik sınıflandırımıştır. Bu çalışma, orman ve ağaç ile ilgilenen araştırmacıların nokta bulutlarının sınıflandırıması probleminde yararlanabilecekleri istatistiksel sınıflandırma yöntemleriyle ilgili bir çalışmadır ve $\mathrm{R}$ program kodlarıyla desteklenmiş gövde çıkarımı ile önemli sonuçları ortaya koymuştur. $\mathrm{R}$ kodlarına https://github.com/mzeybek583/singleTree adresinden ulaşılabilmektedir.

\section{TEŞEKKÜR}

Çalışmada geçen çalışma alanı ölçmelerinde kullanılan GeoSLAM Zeb-Revo cihazını sağlayan GeomaticsGroup Ltd.'ye ve Can Vatandaşlar'a teşekkürlerimi sunarım.

\section{KAYNAKLAR}

3DReshaper. (2020). 3DReshaper Erişim: https://www.3dreshaper.com/fr/

Akar Ö, Güngör O (2015) Integrating multiple texture methods and NDVI to the Random Forest classification algorithm to detect tea and hazelnut plantation areas in northeast Turkey. International Journal of Remote Sensing, 36(2), 442464. doi:10.1080/01431161.2014.995276

Bauwens S, Bartholomeus H, Calders K, Lejeune P (2016) Forest Inventory with Terrestrial LiDAR: A Comparison of Static and Hand-Held Mobile Laser Scanning. Forests, 7(12). doi:10.3390/f7060127

Bienert A, Georgi L, Kunz M, Maas H G, von Oheimb G (2018) Comparison and Combination of Mobile and Terrestrial Laser Scanning for Natural Forest Inventories. Forests, 9(7). doi:10.3390/ 90070395
Bishop C M (2006) Pattern Recognition and Machine Learning: Springer.

Breiman L (2001) Random forests. Machine learning, 45(1), 532.

Brodu N, Lague D (2012) 3D terrestrial lidar data classification of complex natural scenes using a multi-scale dimensionality criterion: Applications in geomorphology. ISPRS Journal of Photogrammetry and Remote Sensing, 68 , 121-134. doi:10.1016/j.isprsjprs.2012.01.006

Cabo C, Del Pozo S, Rodriguez-Gonzalvez P, Ordonez C, Gonzalez-Aguilera D (2018) Comparing Terrestrial Laser Scanning (TLS) and Wearable Laser Scanning (WLS) for Individual Tree Modeling at Plot Level. Remote Sensing, 10(4).

Chen S L, Liu H Y, Feng Z K, Shen C Y, Chen P P (2019) Applicability of personal laser scanning in forestry inventory. Plos One, 14(2). Retrieved from <Go to $|S|>: / /$ WOS:000459806400017

CloudCompare. (2013). Telecom ParisTech (version 2.4) [GPL software]. EDF R\&D. Erişim Linki: http://www.danielgm.net/cc/

Dai W X, Yang B S, Liang X L, Dong Z, Huan R G, Wang Y S, Li W Y (2019) Automated fusion of forest airborne and terrestrial point clouds through canopy density analysis. ISPRS Journal of Photogrammetry and Remote Sensing, 156, 94-107. doi:10.1016/j.isprsjprs.2019.08.008

Dubayah R O, Drake J B (2000) Lidar Remote Sensing for Forestry. Journal of Forestry, 98, 44-52. doi:10.1093/jof/98.6.44

Eren E T, Düzenli T, Alpak E M (2018) The plant species used as edge elements and their usage types: The case of KTU campus. Kastamonu Üniversitesi Orman Fakültesi Dergisi, 18(2), 108-120.

Fritz A, Kattenborn T, Koch B (2013) Uav-Based Photogrammetric Point Clouds - Tree Stem Mapping in Open Stands in Comparison to Terrestrial Laser Scanner Point Clouds. Uav-G2013, 141-146. Retrieved from <Go to IS|>://WOS:000358305000025

Geo-SLAM. (2019). Zeb-Revo Erişim: http://geoslam.com/hardware-products/zeb-revo/

Ghatak A (2017) Machine Learning with R: Springer Singapore. Heinzel J, Ginzler C (2019) A Single-Tree Processing Framework Using Terrestrial Laser Scanning Data for Detecting Forest Regeneration. Remote Sensing, 11(1). doi:10.3390/rs11010060

Hyyppä E, Kukko A, Kaijaluoto R, White J C, Wulder M A, Pyörälä J, Liang X, Yu X, Wang Y, Kaartinen H, Virtanen J-P, Hyyppä J (2020) Accurate derivation of stem curve and volume using backpack mobile laser scanning. ISPRS Journal of Photogrammetry and Remote Sensing, 161, 246-262. doi:10.1016/j.isprsjprs.2020.01.018

James G, Witten D, Hastie T, Tibshirani R (2013) An Introduction to Statistical Learning with Applications in R.

James M R, Quinton J N (2014) Ultra-rapid topographic surveying for complex environments: the hand-held mobile laser scanner (HMLS). Earth Surface Processes and Landforms, 39(1), 138-142. doi:10.1002/esp.3489

Kirasich K, Smith T, Sadler B (2018) Random Forest vs Logistic Regression: Binary Classification for Heterogeneous Datasets. SMU Data Science Review, 1(3), 9.

Kuhn M, Johnson K (2013) Applied Predictive Modeling: Springer.

Lesmeister C (2015) Mastering Machine Learning with R: Packt. 
Liang X L, Kukko A, Kaartinen H, Hyyppa J, Yu X W, Jaakkola A, Wang Y S (2014) Possibilities of a Personal Laser Scanning System for Forest Mapping and Ecosystem Services. Sensors, 14(1), 1228-1248. doi:10.3390/s140101228

Lu X, Guo Q, Li W, Flanagan J (2014) A bottom-up approach to segment individual deciduous trees using leaf-off lidar point cloud data. ISPRS Journal of Photogrammetry and Remote Sensing, 94, 1-12. doi:10.1016/j.isprsjprs.2014.03.014

Maltamo M, Næsset E, Vauhkonen J (2014) Forestry Applications of Airborne Laser Scanning- Concepts and Case Studies.

MGM. (2019). Trabzon meteoroloji istasyonu iklim verileri. Ankara

Nurunnabi A, Sadahiro Y, Lindenbergh R (2017) Robust Cylinder Fitting in Three-Dimensional Point Cloud Data. ISPRS International Archives of the Photogrammetry, Remote Sensing and Spatial Information Sciences, XLII-1/W1, 63-70. doi:10.5194/isprs-archives-XLII-1-W1-63-2017

Özdemir i (2013) Yersel lazer tarama ile tek ağaç özelliklerinin belirlenmesi. Türkiye Ormancılık Dergisi, 14(1), 40-47.

Pal R (2017) Predictive Modeling of Drug Sensitivity: Academic Press.

Pessoa G G, Santos R C, Carrilho A C, Galo M, Amorim A (2019) Urban Scene Classification Using Features Extracted from Photogrammetric Point Clouds Acquired by Uav. ISPRS International Archives of the Photogrammetry, Remote Sensing and Spatial Information Sciences, XLII-2/W13, 511518. doi:10.5194/isprs-archives-XLII-2-W13-511-2019

Robert I. K (2015) R in Action Data analysis and graphics with R. USA: Manning Publications Co.

Rusu R B (2009) Semantic 3D Object Maps for Everyday Manipulation in Human Living Environments.

Sammartano G, Spanò A (2018) Point clouds by SLAM-based mobile mapping systems: accuracy and geometric content validation in multisensor survey and stand-alone acquisition. Applied Geomatics, 10(4), 317-339. doi:10.1007/s12518-018-0221-7
Tomaštík J, Saloň Š, Tunák D, Chudý F, Kardoš M (2017) Tango in forests - An initial experience of the use of the new Google technology in connection with forest inventory tasks. Computers and Electronics in Agriculture, 141, 109117. doi:10.1016/j.compag.2017.07.015

Vatandaşlar C, Zeybek M (2020) Application of handheld laser scanning technology for forest inventory purposes in the NE Turkey. Turkish Journal of Agriculture and Forestry. doi:10.3906/tar-1903-40

Wang P, Li R H, Bu G C, Zhao R (2019) Automated low-cost terrestrial laser scanner for measuring diameters at breast height and heights of plantation trees. Plos One, 14(1). doi:10.1371/journal.pone.0209888

Weinmann M (2016) Reconstruction and Analysis of 3D Scenes: Springer.

Wilcox R R (2010) Fundamentals of Modern Statistical Methods: Springer.

Xiong L, Wang G Q, Bao Y, Zhou X, Wang K, Liu H L, Sun X H, Zhao R B (2019) A Rapid Terrestrial Laser Scanning Method for Coastal Erosion Studies: A Case Study at Freeport, Texas, USA. Sensors, 19(15). doi:10.3390/s19153252

Yener H, Koç A, Çoban H O (2006) Uzaktan Algılama Verilerinde Sınıflandırma Doğruluğunun Belirlenmesi Yöntemleri. İstanbul Üniversitesi Orman Fakültesi Dergisi, 56(2), 71-88.

Yrttimaa T, Saarinen N, Luoma V, Tanhuanpaa T, Kankare V, Liang X L, Hyyppa J, Holopainen M, Vastaranta M (2019) Detecting and characterizing downed dead wood using terrestrial laser scanning. ISPRS Journal of Photogrammetry and Remote Sensing, 151, 76-90. doi:10.1016/j.isprsjprs.2019.03.007

Zeybek M (2019) El-tipi LiDAR ölçme sistemleri ve 3B veri işleme. Türkiye Lidar Dergisi, 1(1), 10-15.

Zhang W M, Qi J B, Wan P, Wang H T, Xie D H, Wang X Y, Yan G J (2016) An Easy-to-Use Airborne LiDAR Data Filtering Method Based on Cloth Simulation. Remote Sensing, 8(6), 501. doi:10.3390/rs8060501 